\title{
Efektivitas Ekstrak Daun Beluntas (Pluchea indica Less) sebagai Inhibitor Korosi pada Material Baja Karbon dalam Media $\mathrm{NaCl}$ 3,5\%
}

\section{Effectiveness of Beluntas (Pluchea indica Less) Leaf Extracts as Corrosion Inhibitor Carbon Steel in 3,5\% NaCl Solution}

\author{
${ }^{1)}$ Ramlah, ${ }^{2)}$ Mohammad Wijaya M, ${ }^{3)}$ Diana Eka Pratiwi \\ 123) Jurusan Kimia Fakultas Matematika dan Ilmu Pengetahuan Alam \\ Universitas Negeri Makassar, Jl. Dg Tata Raya Makassar, Makassar 90224 \\ Email:ramlahmahuddin@gmail.com
}

\begin{abstract}
ABSTRAK
Penelitian ini merupakan penelitian eksperimen yang bertujuan untuk mengetahui pengaruh variasi konsentrasi inhibitor ekstrak daun beluntas (Pluchea indica Less.) terhadap laju korosi baja karbon dan karakteristik permukaan baja karbon sebelum dan sesudah direndam dalam media $\mathrm{NaCl}$ 3,5\% tanpa dan dengan adanya inhibitor. Media korosif $\mathrm{NaCl} 3,5 \%$ direaksikan dengan ekstrak daun beluntas untuk memperlambat proses oksidasi Fe dengan variasi konsentrasi 0 ppm, 500 ppm, 1000 ppm, 1500 ppm dan 2000 ppm dan direndam selama 2, 4 dan 6 hari. Pengukuran laju korosi dilakukan dengan metode Weight loss dan polarisasi potensiodinamik. Karakterisasi baja karbon dilakukan menggunakan instrumen Fourier Transform Infra Red (FT-IR) dan Scanning Electron Microscopy-Energy Dispersive Spectroscopy (SEMEDS). Metode Weight loss dan polarisasi potensiodinamik menunjukkan nilai laju korosi terkecil pada perendaman selama 6 hari dengan konsentrasi inhibitor $2000 \mathrm{ppm}$ yaitu masing-masing sebesar 1,5451 mmpy dan 1,5514 mmpy dengan efisiensi inhibisi sebesar 91\%. Hasil penelitian menunjukkan bahwa semakin besar konsentrasi ekstrak dan semakin lama perendaman maka laju korosi semakin kecil dan efisiensi inhibisi semakin besar. Analisis FT-IR menunjukkan gugus fungsi yang teradsorpsi ke permukaan baja karbon yaitu $\mathrm{O}-\mathrm{H}, \mathrm{C}=\mathrm{C}$ dan $-\mathrm{CO}-$. Selain itu pada daerah sidik jari mengindikasikan ikatan Fe-O yang merupakan kompleks antara logam dengan senyawa ekstrak. Hasil analisis SEM-EDS menunjukkan bahwa pada permukaan baja karbon yang direndam dalam larutan $\mathrm{NaCl}$ 3,5\% tanpa adanya inhibitor terbentuk retakan yang lebih banyak dibandingkan permukaan baja karbon yang direndam dalam larutan $\mathrm{NaCl} 3,5 \%$ dengan adanya ekstrak daun beluntas. Persentase $\mathrm{Fe}$ untuk baja karbon yang direndam tanpa adanya inhibitor sebesar 70,88\% sedangkan untuk baja karbon yang direndam dengan adanya inhibitor sebesar $77,83 \%$.

Kata kunci: Laju Korosi, Baja Karbon, $\mathrm{NaCl}$ 3,5\%, Inhibitor, Ekstrak Daun Beluntas
\end{abstract}




\begin{abstract}
This research is an experiment research aimed to determine the effect of variations concentration of beluntas leaf extract on the corrosion rate of carbon steel and characteristics surface before and after immersed in $3,5 \% \mathrm{NaCl}$ solution without and presence of inhibitors. Corrosive reacted with beluntas leaf extract to slow the process of oxidation Fe with various concentrations of $0 \mathrm{ppm}, 500 \mathrm{ppm}, 1000 \mathrm{ppm}, 1500 \mathrm{ppm}$ and $2000 \mathrm{ppm}$ and immersion 2, 4 and 6 days. Measurement of corrotion rate by weight loss and potentiodynamic polarization method. Characterization of carbon steel used Fourier Transform Infra Red (FTIR) and Scanning Electron Microscopy-Energy Dispersive Spectroscopy (SEM-EDS). Weight loss and potentiodynamic polarization methode showed that the smallest corrosion rate at 6 days immersion with an extract concentration of $2000 \mathrm{ppm}$, each of 1,5451 mmpy and 1,5514 mmpy with an efficiency of $91 \%$. The results showed that the greater the extract concentration and the longer immersion the smaller the corrosion rate and the greater the eficciency. The fuctional groups adsorbed to the aurface of carbon steel are $\mathrm{O}-\mathrm{H}, \mathrm{C}=\mathrm{C}$ and $-\mathrm{CO}$-. Also in the fingerprint area indicate $\mathrm{Fe}-\mathrm{O}$ bond is a complex between metal and extract compounds. The results of SEMEDS analysis showed that on the carbon steel surface immersed in 3,5\% $\mathrm{NaCl}$ solution without inhibitor formed more cracks than carbon steel surface immersed in 3,5\% $\mathrm{NaCl}$ solution in the presence of beluntas leaf extract. Percentace of Fe for carbon steel immersed without an inhibitor is $70,88 \%$ while fore carbon steel immersed in the presence of an inhibitor of $77,83 \%$.
\end{abstract}

Keywords: Corrosion Rate, Carbon Steel, 3,5\% NaCl, Inhibitor, Beluntas Leaf Extract

\section{PENDAHULUAN}

Indonesia merupakan salah satu negara yang sektor perindustriannya berkembang dengan sangat pesat. Keberadaan industri tersebut tidak lepas dari pemanfaatan logam dan paduannya sebagai bahan baku pembuatan alat-alat produksi. Menurut Saputra, dkk (2014) baja karbon merupakan jenis logam paduan yang banyak digunakan dalam ranah perindustrian sebagai bahan utama konstruksi pada kilang minyak, pabrik makanan, pembangkit listrik, perusahaan air minum dan industri kimia lainnya. Hal tersebut dikarenakan baja karbon memiliki kekuatan dan keuletan yang baik serta harganya yang relatif murah. Namun, penggunaan baja karbon juga memiliki kelemahan diantaranya ketahanan terhadap korosi sangat rendah (Akmal, 2009).

Korosi merupakan proses degradasi material akibat adanya proses reaksi kimia dengan lingkungannya (air, udara, tanah dan zat-zat kimia). Korosi menjadi salah satu masalah besar yang dihadapi oleh kelompok industri maju. Kerugian 
yang diakibatkan oleh korosi menimbulkan dampak ekonomi yang cukup besar. Di negara maju seperti Amerika Serikat, kerugian yang diakibatkan oleh korosi di sektor industri mencapai US\$ 276 juta per tahun (Koch, et al., 2001).

Metode pengendalian korosi dengan inhibitor korosi merupakan salah satu metode yang umum dan perkembangannya cukup pesat karena prosesnya yang sederhana dan biaya yang murah. Pengendalian korosi menggunakan inhibitor mampu memperpanjang umur penggunaan logam (Oguzie, et al., 2009).

Inhibitor korosi didefinisikan sebagai suatu zat yang apabila ditambahkan dalam jumlah tertentu ke dalam lingkungan akan menurunkan korosi lingkungan terhadap logam. Umumnya inhibitor korosi berasal dari senyawa organik maupun senyawa anorganik. Penggunaan inhibitor dari senyawa anorganik telah banyak digunakan, namun penggunaan inhibitor tersebut tidak ramah lingkungan dan memiliki toksisitas yang tinggi, sehingga inhibitor tersebut perlu digantikan dengan senyawa lain yang bersifat nontoksik dan mampu mendegradasi secara biologis, namun tetap bernilai ekonomis dan mampu mengurangi laju korosi secara signifikan (Handani dan Megi, 2012).

Beberapa penelitian telah mencatat keefektifan ekstrak tumbuhan dalam menginhibisi korosi baja. Telah dilaporkan bahwa kulit jengkol (Pithecellobium jiringa) yang mengandung senyawa fenolik, flavonoid, terpenoid dan alkaloid mampu menurunkan laju korosi pada baja karbon hingga 88,23\% (Rozi, dkk., 2014). Daun jambu biji (Psidium guajava L) yang mengandung tanin, polifenolat, flavonoid, monoterpenoid, siskuiterpen, alkaloid, kuinon dan saponin efektif mengurangi laju korosi pada baja hingga $88,76 \%$ pada konsentrasi ekstrak 5\% (Sari, dkk., 2013). Sedangkan daun ekor naga (Rhaphidophora pinnata Scott.) dengan konsentrasi 8,0 g/L dan suhu perendaman $30 \mathrm{oC}$ efisien menghambat korosi baja hingga 93,85\% (Yuningsih, dkk., 2016).

Dari beberapa penelitian yang telah dilakukan sebelumnya, dapat diketahui bahwa beberapa senyawa organik yang berasal dari ekstrak tumbuhan dapat digunakan sebagai inhibitor korosi. Salah satu tumbuhan yang memiliki potensi untuk dijadikan inhibitor adalah daun beluntas (Pluchea indca Less). Daun beluntas memiliki kandungan alkaloid $(0,316 \%)$, flavonoid $(4,18 \%)$, serta tanin (2,351\%) (Dalimartha, 1999). Senyawa yang dimiliki oleh daun beluntas dapat berfungsi sebagai inhibitor korosi karena memiliki gugus fungsi yang dapat berikatan dengan logam.

Natrium klorida atau garam dapur merupakan salah satu larutan elektrolit kuat yang di dalam air akan terurai menjadi ion-ion penyusunnya (baik berupa kation maupun anion). Semakin tinggi konsentrasi $\mathrm{NaCl}$ di dalam larutan maka konduktivitas larutan semakin besar, sehingga meningkatkan laju korosi pada baja. Namun, semakin pekat konsentrasi 
$\mathrm{NaCl}$ maka akan terjadi penurunan kelarutan sehingga laju korosi akan berkurang. Hal ini disebabkan karena kejenuhan dari larutan $\mathrm{NaCl}$ sehingga laju korosi optimum baja karbon berada pada konsentrasi $\mathrm{NaCl} 3-3,5 \%$ ((Jones, 1992).

Uraian di atas menjadi dasar pemikiran peneliti untuk melakukan pengujian efektivitas ekstrak daun beluntas (Pluchea indica Less.) sebagai inhibitor korosi pada material baja karbon dalam media $\mathrm{NaCl} 3,5 \%$. Melalui penelitian ini, penggunaan ekstrak daun beluntas diharapkan dapat menjadi inhibitor korosi yang ramah lingkungan, di samping itu juga agar dapat meningkatkan nilai ekonomis dari tanaman beluntas yang biasanya hanya digunakan sebagai tanaman pagar saja.

\section{METODE PENELITIAN}

\section{A. Alat dan Bahan}

Alat-alat yang digunakan dalam penelitian ini antara lain neraca analitik Cheetah FA2204B, wadah maserasi, jangka sorong, gerinda, blender, rotary evaporator Heidolph VV2000, plat tetes, pompa vakum, corong bucner, elektroda Pt, elektroda Ag, potensiostat EDAQ ED410, Fourier Transform Infra Red (FTIR) Shimadzu prestige 21, Scanning Electron Microscopy- Energy Dispersive Spectroscopy (SEM-EDS) Hitachi Flexsem 1000 serta peralatan gelas yang umum digunakan di Laboratorium.

Bahan yang digunakan dalam penelitian ini meliputi lempengan baja karbon rendah dengan komposisi karbon $(0,04 \%)$, Silikon $(0,014 \%)$, Mangan $(0,165 \%)$, Posfor $(0,017 \%)$, Sulfur $(0,006 \%)$, dan Boron $(0,0021)$, kertas amplas, metanol teknis, Aseton teknis, Natrium Klorida $(\mathrm{NaCl})$ p.a, kertas saring Whatmann 41, akuades, akuabides, $\mathrm{FeCl} 3$ 1\%, pereaksi Wagner, pereaksi Dragen Droff.

\section{B. Prosedur Kerja}

\section{Persiapan spesimen baja}

Permukaan plat baja karbon dihaluskan dengan menggunakan kertas amplas silika karbid. Plat baja karbon yang telah halus kemudian dipotong dengan ukuran 30x20x1 mm. Permukaan baja karbon dibilas dengan akuades dan dilanjutkan dengan menggunakan aseton. Selanjutnya spesimen baja karbon dikeringkan. Setelah kering, spesimen baja karbon ditimbang dan hasil penimbangan dinyatakan sebagai berat awal $\left(\mathrm{m}_{1}\right)$.

\section{Pembuatan ekstrak daun beluntas (Pluchea indica Less)}

Daun beluntas segar dicuci menggunakan air mengalir. Setelah dicuci, lalu dipotong kecil-kecil dan dikeringkan pada suhu ruang. Daun beluntas yang telah kering kemudian dihaluskan menggunakan blender dan ditimbang sebanyak 2000 g. Sampel tersebut dimaserasi dengan metanol selama 3 hari. Ekstrak yang didapat kemudian disaring menggunakan alat pompa vakum yang dihubungkan dengan erlenmeyer dan corong buchner yang berisi kertas saring. Filtrat yang diperoleh selanjutnya diuapkan pelarutnya menggunakan rotary evaporator dengan kecepatan 50 
rpm dan suhu $40^{\circ} \mathrm{C}$ sehingga didapatkan ekstrak pekat (bebas pelarut).

\section{Uji fitokimia ekstrak daun beluntas (Pluchea Indica Less)}

Setelah diperoleh ekstrak kental, selanjutnya dilakukan uji pendahuluan terhadap ekstrak kental yang diperoleh dengan berbagai pereaksi diantaranya pereaksi $\mathrm{FeCl} 3$ (tanin), Dragendroff (alkaloid) dan Wagner (alkaloid).

\section{Pembuatan larutan $\mathrm{NaCl} 3,5 \%$}

Larutan $\mathrm{NaCl} \quad 3,5 \%$ dibuat dengan melarutkan 35 g padatan $\mathrm{NaCl}$ p.a ke dalam akuabides. Selanjutnya, dimasukkan ke dalam labu takar 1000 $\mathrm{mL}$ dan ditambahkan akuabides hingga tanda batas lalu dihomogenkan.

\section{Pembuatan larutan medium korosif dengan adanya penambahan ekstrak daun beluntas}

Ekstrak pekat yang telah diperoleh divariasikan konsentrasinya yaitu 500 ppm, 1000 ppm, 1500 ppm dan 2000 ppm dari larutan induk 5000 ppm. Masing-masing variasi konsentrasi tersebut diukur sebanyak $50 \mathrm{~mL}$ kemudian ditambahan larutan $\mathrm{NaCl} 3,5 \%$ sebanyak $50 \mathrm{~mL}$ sehingga didapatkan medium korosif $\mathrm{NaCl} 3,5 \%$ dengan adanya variasi konsentrasi ekstrak daun beluntas

\section{Penentuan laju korosi berdasarkan metode kehilangan massa}

Penentuan laju korosi dengan metode kehilangan massa dilakukan dengan cara baja direndam dalam larutan medium korosif $\mathrm{NaCl} 3,5 \%$ tanpa dan dengan adanya variasi inhibitor dan variasi waktu perendaman 2 hari, 4 hari dan 6 hari. Baja selanjutnya dibersihkan, dicuci menggunakan aseton dan dikeringkan. Setelah kering, baja ditimbang dan hasil penimbangan dinyatakan sebagai massa akhir $\left(\mathrm{m}_{2}\right)$ sehingga didapatkan kehilangan massa $(\Delta \mathrm{m})$ dengan mengurangkan massa awal baja dengan massa akhir setelah perendaman. Kehilangan massa dilakukan untuk menghitung laju korosi dan efisiensi inhibisi ekstrak daun beluntas.

\section{Pengukuran polarisasi potensiodinamik \\ Pengukuran polarisasi}

potensidinamik dilakukan dengan cara menggunakan baja sebagai elektroda kerja, elektroda Pt sebagai elektroda pembantu dan $\mathrm{Ag} / \mathrm{AgCl}$ sebagai elektroda pembanding. Pengukuran polarisasi potensiodinamik dilakukan dalam medium $\mathrm{NaCl} 3,5 \%$ yang mengandung campuran ekstrak dengan variasi konsentrasi 0 ppm, 500 ppm, 1000 ppm, 1500 ppm, dan 2000 ppm. Ketiga elektorda dicelupkan ke dalam bejana berisi medium korosif tanpa dan dengan adanya inhibitor berbagai variasi konsentrasi. Kemudian dihubungkan dengan potensiometer dan diukur potensial sehingga diperoleh kurva hubungan antara potensial (V) dengan log arus (mA). 
8. Analisis Menggunakan

Spektrofotometer Fourier
Transform Infra-Red (FTIR) dan
instrumen Scanning Electron
Microscopy-Energy Dispersive
Spectroscopy (SEM-EDS)

Analisis FTIR dan SEM-EDS dilakukan pada sampel ekstrak daun beluntas dan produk korosi baja karbon yang telah direndam dalam media korosif $\mathrm{NaCl} 3,5 \%$ dengan adanya ekstrak daun beluntas.

\section{HASIL DAN PEMBAHASAN}

\section{Ekstraksi Daun Beluntas (Pluchea indica Less.)}

Ekstrak daun beluntas diperoleh dengan metode maserasi dalam pelarut metanol. Proses maserasi dilakukan pada suhu ruang selama 3 hari. Maserat yang diperoleh disaring dan filtratnya dievaporasi menggunakan rotary vacum evaporator untuk menguapkan pelarutnya. Ekstrak hijau pekat yang telah bebas pelarut ditunjukkan pada Gambar 1.

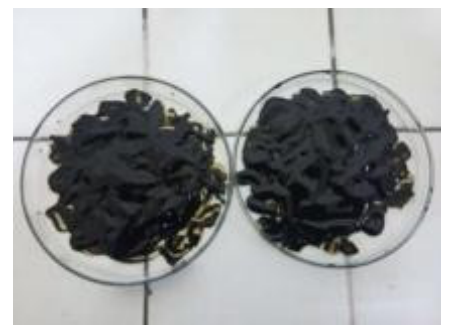

Gambar 1. Ekstrak pekat daun beluntas

Ekstrak yang telah diperoleh kemudian dilakukan pengujian fitokimia. Hasil uji fitokimia ekstrak ditunjukkan pada Tabel 1 dan Gambar 2.

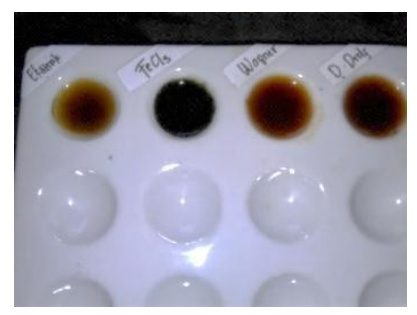

Gambar 2. Hasil Uji Fitokimia

Tabel 1. Hasil Uji Fitokimia Ekstrak Metanol Daun Beluntas

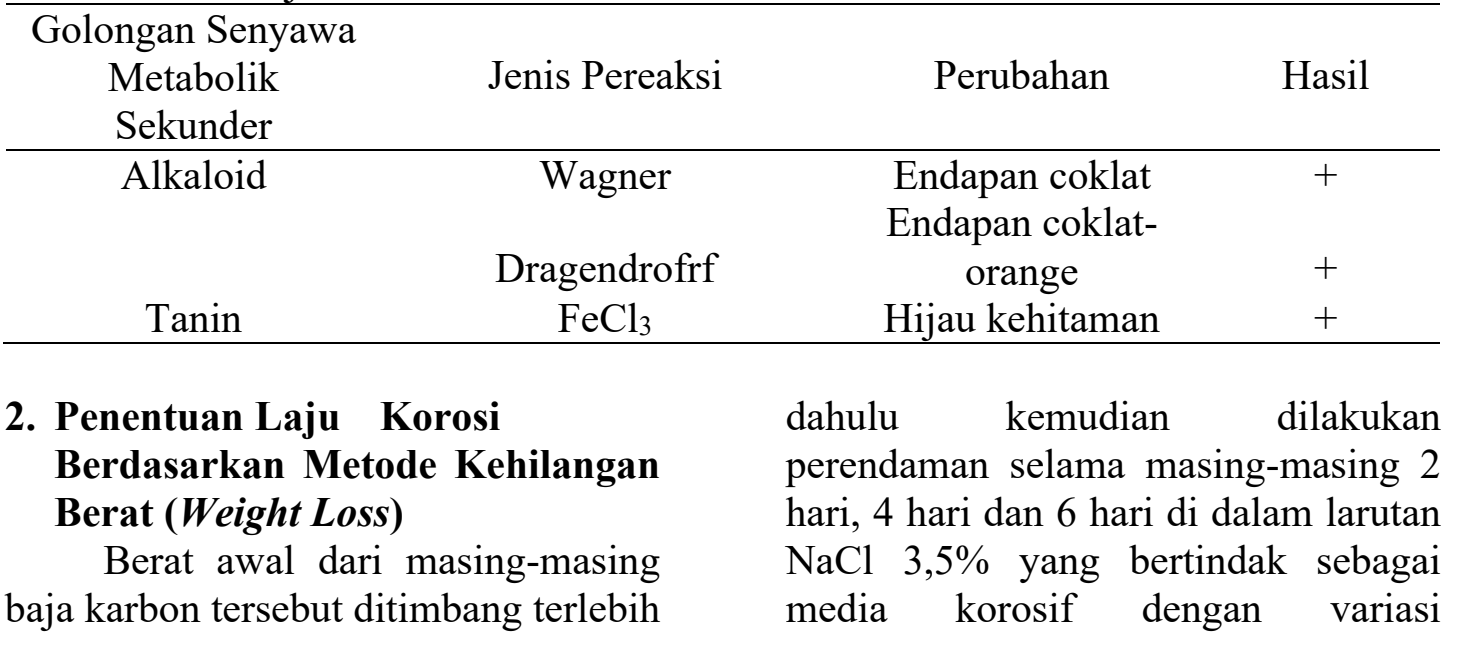


konsentrasi inhibitor ekstrak daun beluntas yang berbeda yaitu $0 \mathrm{ppm}, 500$ ppm, 1000 ppm, 1500 ppm dan 2000 ppm. Setelah perendaman, dilakukan pembersihan kembali sampel dan dilakukan penimbangan berat akhir, sehingga dapat diperoleh selisih berat baja karbon.

Saat dilakukan perendaman pada larutan $\mathrm{NaCl} 3,5 \%$ tanpa penambahan inhibitor terjadi perubahan warna dari bening menjadi jingga pada hari ke 2 , ke 4 dan hari ke 6. Warna jingga tersebut berubah lebih pekat pada waktu perendaman yang lebih lama. Perubahan warna disebabkan karena adanya produk korosi berupa endapan berwarna jingga. Sedangkan untuk larutan $\mathrm{NaCl}$ 3,5\% yang ditambahkan inhibitor yang awalnya berwarna hijau pucat berubah menjadi hijau kehitaman seiring lamanya perendaman seperti yang terlihat pada Gambar 3.

\section{Larutan sebelum perendaman baja} karbon

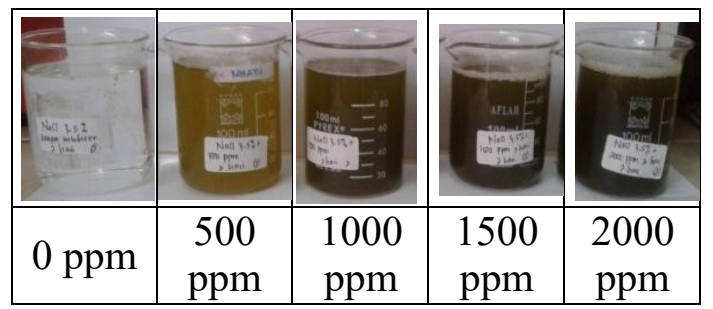

Larutan setelah perendaman baja karbon selama 2 hari

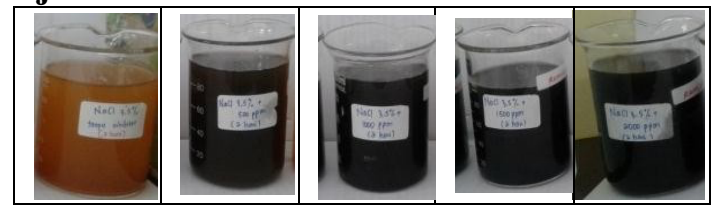

\begin{tabular}{|c|c|c|c|c|}
\hline 0 ppm & $\begin{array}{c}500 \\
\text { ppm }\end{array}$ & $\begin{array}{c}1000 \\
\text { ppm }\end{array}$ & $\begin{array}{c}1500 \\
\text { ppm }\end{array}$ & $\begin{array}{c}2000 \\
\text { ppm }\end{array}$ \\
\hline
\end{tabular}

Larutan setelah perendaman baja karbon selama 4 hari

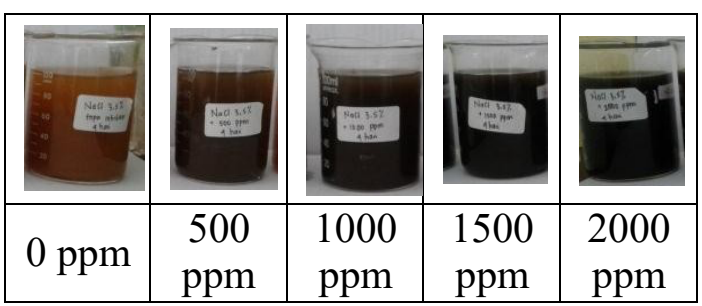

Larutan setelah perendaman baja karbon selama 6 hari

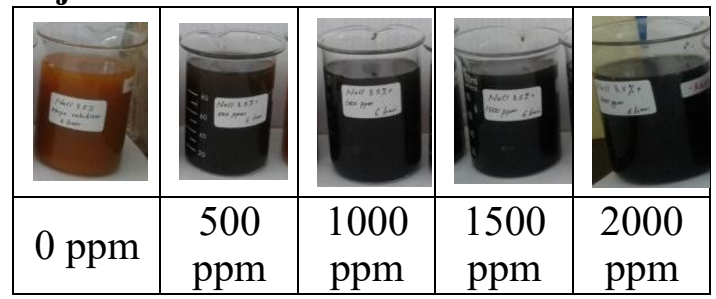

Gambar 3. Perubahan warna larutan $\mathrm{NaCl} 3,5 \%$ tanpa inhibitor (0 ppm) dan dengan adanya inhibitor (500 ppm, 1000 ppm, 1500 ppm dan 2000 ppm).

Sampel baja karbon awalnya berwarna silver seperti yang ditunjukkan pada Gambar 4, setelah dilakukan perendaman pada media $\mathrm{NaCl} 3,5 \%$ tanpa dan dengan adanya inhibitor mengalami perubahan warna. Dimana untuk sampel yang direndam pada media $\mathrm{NaCl} 3,5 \%$ tanpa adanya inhibitor menunjukkan produk korosi yang ditandai dengan warna orange pada permukaan sampel dan semakin banyak seiring lamanya perendaman seperti yang ditunjukkan pada Gambar 5. 


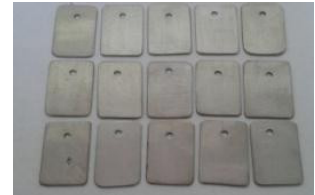

Gambar 4. Baja Karbon sebelum perendaman

Baja karbon setelah perendaman selama 2 hari

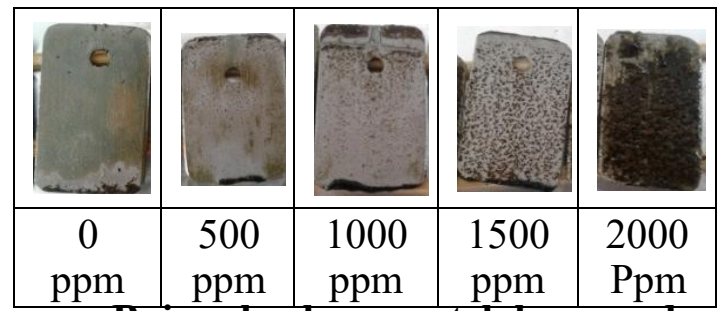

Baja karbon setelah perendaman selama 4 hari

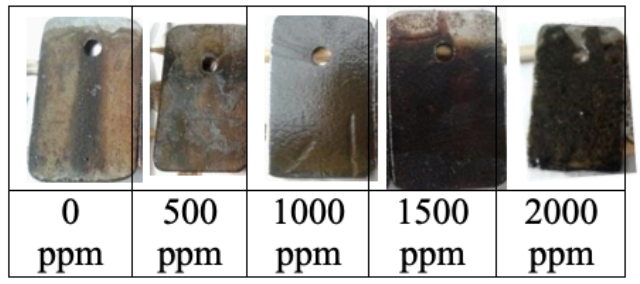

\section{Baja karbon setelah perendaman selama 6 hari}

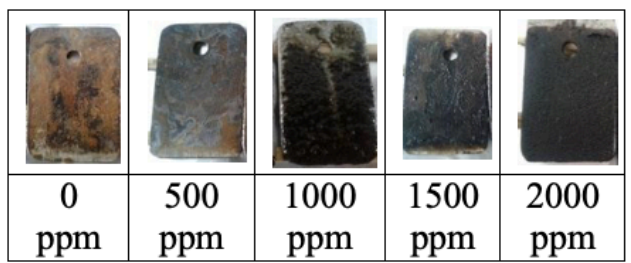

Gambar 5 Baja karbon setelah perendaman, tanpa inhibitor $(0 \mathrm{ppm})$ dan dengan adanya inhibitor (500 ppm, 1000 ppm, 1500 ppm dan 2000 ppm).

Grafik pada Gambar 6 menunjukkan bahwa laju korosi baja karbon menurun dengan bertambahnya konsentrasi inhibitor. Penambahan inhibitor dapat menurunkan laju korosi karena dapat membentuk lapisan pelindung di permukaan baja karbon yang berfungsi sebagai penghalang antara logam dengan larutan $\mathrm{NaCl}$ $3,5 \%$.

Gambar 6. Grafik hubungan antara

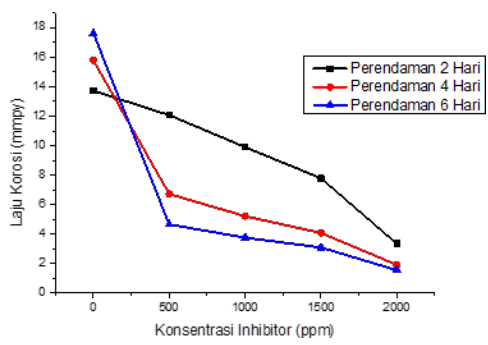

konsentrasi inhibitor dan laju korosi

Efisiensi inhibisi semakin meningkat seiring dengan bertambahnya konsentrasi inhibitor dan bertambahnya waktu perendaman seperti yang ditunjukkan pada Gambar 7.

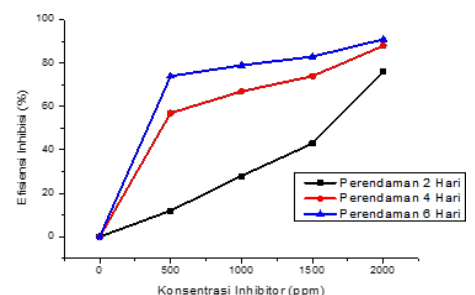

Gambar 7. Grafik hubungan antara konsentrasi inhibitor dan efisiensi inhibitor.

\section{Penentuan Laju Korosi Berdasarkan Metode polarisasi potensiodinamik}

Polarisasi potensiodinamik merupakan metode penentuan laju korosi serta efisiensi inhibisi berdasarkan hubungan potensial dan arus. 


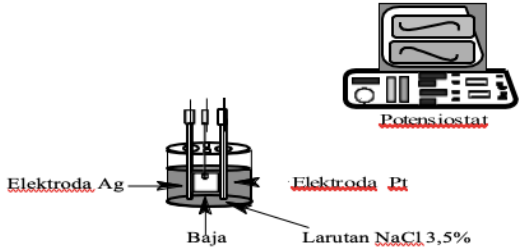

Gambar 8. Skema rangkaian alat polarisasi potensiostat

Baja karbon direndam dalam larutan $\mathrm{NaCl} 3,5 \%$ tanpa dan dengan adanya inhibitor selama 2 hari, 4 hari dan 6 hari. Kurva polarisasi pada baja karbon dalam media $\mathrm{NaCl} 3,5 \%$ tanpa dan dengan adanya inhibitor ditunjukkan pada Gambar 9.

(a)

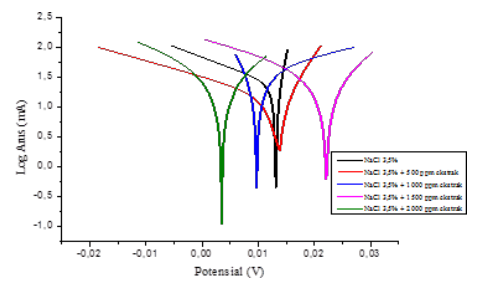

(b)

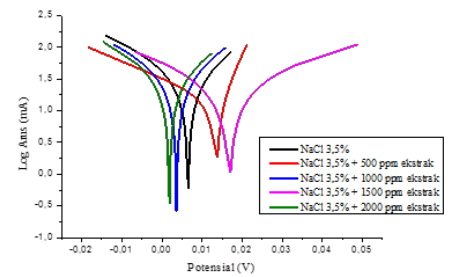

(c)

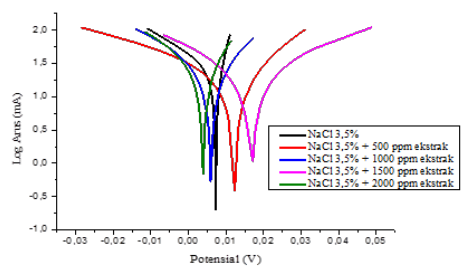

Gambar 9. Kurva Polarisasi dari baja karbon dalam media $\mathrm{NaCl} 3,5 \%$ tanpa dan dengan adanya inhibitor (a) perendaman 2 hari, (b) perendaman 4 hari, (c) perendaman 6 hari.

Ekstrak daun beluntas termasuk mixed inhibitor karena memiliki selisih potensial korosi tidak melebihi $85 \mathrm{mV}$ dan juga dapat dilihat dari bentuk kurva polarisasi pada Gambar 9 penambahan inhibitor daun beluntas ini terjadi pergeseran kurva kearah anodik dan katodik.

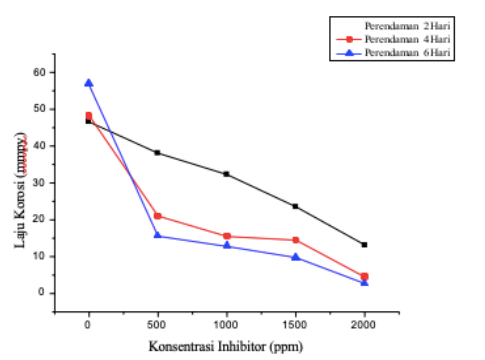

Gambar 10. Grafik hubungan antara konsentrasi inhibitor dan laju korosi

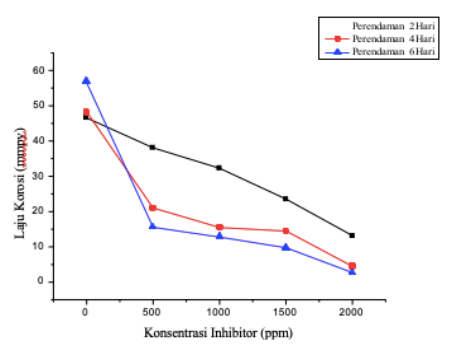

Gambar 11. Grafik hubungan antara konsentrasi inhibitor dan efisiensi inhibitor.

Pengujian dengan metode
polarisasi potensiodinamik ini
menunjukkan pola yang sama dengan
metode weight loss dimana laju korosi
menurun seiring dengan meningkatnya
konsentrasi inhibitor dan efisiensi
meningkat seiring dengan
meningkatnya konsentrasi inhibitor.




\section{Analisis Fourier Transform Infra Red (FTIR)}

Lapisan yang terbentuk pada permukaan baja karbon yang telah direndam selama 6 hari dalam larutan $\mathrm{NaCl} 3,5 \%$ tanpa dan dengan adanya inhibitor $2000 \mathrm{ppm}$ di analisis menggunakan FTIR. Hasil analisis FTIR dapat dilihat pada Gambar 12.
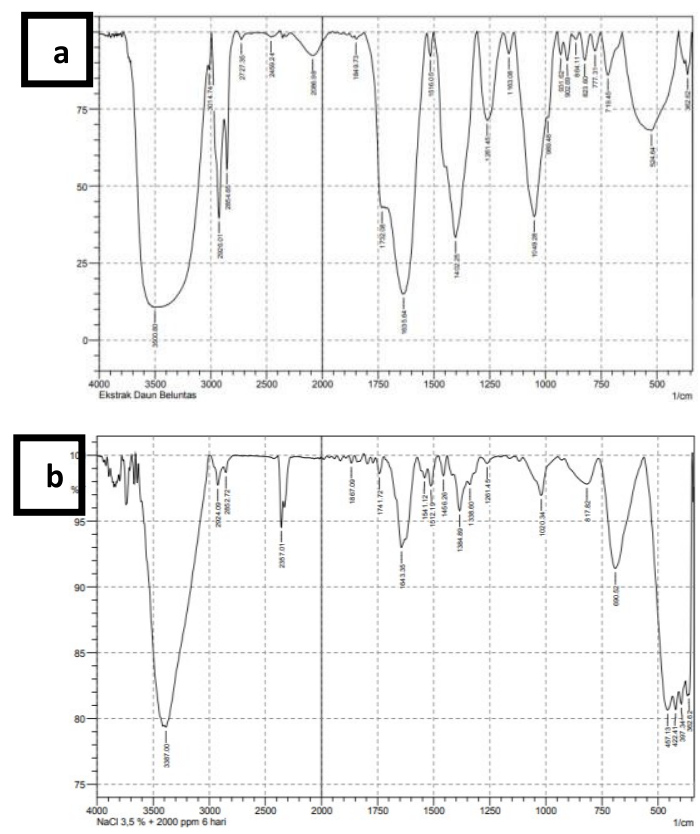

Gambar 12. Spektrum FTIR (a) Ekstrak daun beluntas (b) lapisan adsorpsi pada Permukaan baja karbon setelah perendaman dalam larutan $\mathrm{NaCl} 3,5 \%$ selama 6 hari dengan penambahan ekstrak daun beluntas $2000 \mathrm{ppm}$.

Pada Gambar 12(a) menunjukkan adanya beberapa gugus fungsi yang terkandung dalam senyawa ekstrak daun beluntas seperti gugus $\mathrm{O}-\mathrm{H}$ pada angka gelombang
$3500,80 \mathrm{~cm}^{-1}$, gugus $\mathrm{C}-\mathrm{H}$ alifatik pada angka gelombang $2854,65 \mathrm{~cm}^{-1}$, gugus $\mathrm{C}=\mathrm{O}$ pada angka gelombang 1635,64 $\mathrm{cm}^{-1}$, gugus $\mathrm{C}=\mathrm{C}$ pada angka gelombang 1516,05 $\mathrm{cm}^{-1}$ dan gugus CO- pada angka gelombang 1049,28 $\mathrm{cm}^{-1}$.

Sedangkan pada Gambar 12(b) menunjukkan adanya gugus fungsi $\mathrm{O}-$ $\mathrm{H}$ pada angka gelombang 3387,00 , gugus fungsi $\mathrm{C}=\mathrm{C}$ pada angka gelombang 1512,19 $\mathrm{cm}^{-1}$ dan gugus fungsi - CO- pada angka gelombang $1020,34 \mathrm{~cm}^{-1}$. Pada daerah sidik jari menunjukkan ikatan kompleks antara logam dengan senyawa ekstrak yaitu pada panjang gelombang $457,13 \mathrm{~cm}^{-1}$, $422,41 \mathrm{~cm}^{-1}, \quad 397,34 \mathrm{~cm}^{-1}, \quad$ dan $362,62 \mathrm{~cm}^{-1}$ mengindikasikan adanya ikatan Fe-O.

\section{Analisis Scanning Electron Microscopy- Energy Dispersive Spectroscopy (SEM-EDS)}

Plat baja yang telah direndam pada media $\mathrm{NaCl} 3,5 \%$ dengan konsentrasi inhibitor 0 ppm dan 2000 ppm dengan lama perendaman 6 hari selanjutnya dianalisis menggunakan SEM-EDS. Hasil analisis SEM-EDS dapat dilihat pada Gambar 13 dan 14.
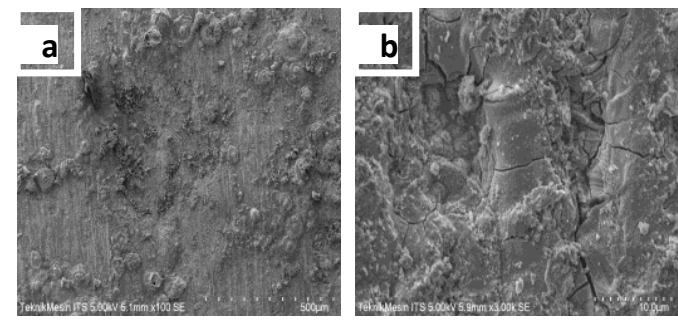

Gambar 13. Morfologi permukaan baja karbon yang direndam selama 6 hari dalam media $\mathrm{NaCl} 3,5 \%$ inhibitor 
0 ppm (a) perbesaran 100x (b) perbesaran 3000x

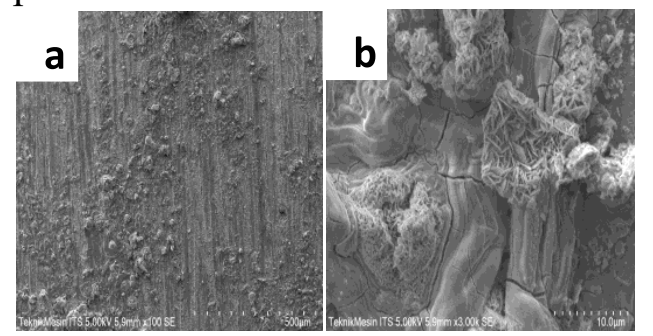

Gambar 14. Morfologi permukaan baja karbon yang direndam selama 6 hari dalam media $\mathrm{NaCl} 3,5 \%$ dengan penambahan inhibor 2000 ppm (a) perbesaran 100x (b) perbesaran 3000x

Hasil SEM baja karbon dengan inhibitor korosi 0 ppm seluruh permukaan telah mengalami kerusakan yang ditandai dengan adanya retakan (crack) dan juga gumpalan-gumpalan menunjukkan adanya produk korosi yang terbentuk. Sedangkan baja karbon yang telah ditambahkan inhibitor korosi 2000 ppm terlihat bahwa pada permukaan baja karbon terbentuk gumpalan yang tidak menutupi seluruh permukaan baja, dan terlihat retakan (crack) yang tidak tersebar merata pada permukaan baja karbon. Oleh karena itu, dari hasil SEM kedua sampel disimpulkan bahwa pada sampel dengan adanya penambahan inhibitor, crack lebih sedikit sehingga laju korosi akan lebih kecil.

Analisis EDS menunjukkan bahwa baja karbon yang direndam dalam media $\mathrm{NaCl}$ 3,5\% tanpa adanya inhibitor memiliki persentase atom $\mathrm{Fe}$ sebesar 70,88\%. Sedangkan baja karbon yang direndam dalam media $\mathrm{NaCl} 3,5 \%$ dengan adanya penambahan inhibitor 2000 ppm memiliki persentase atom $\mathrm{Fe}$ sebesar $77,83 \%$. Kandungan besi yang rendah pada baja karbon yang direndam dalam media $\mathrm{NaCl} 3,5 \%$ tanpa adanya inhibitor disebabkan karena logam besi yang teroksidasi lebih banyak sehingga besi akan semakin kehilangan elektron dan kehilangan massa.

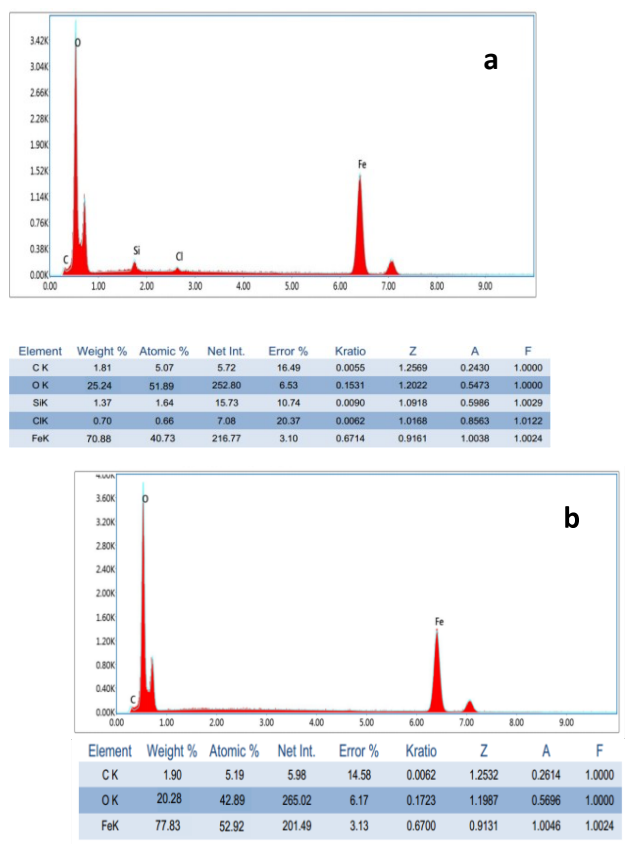

Gambar 15. Grafik EDS baja karbon dalam media $\mathrm{NaCl} 3,5 \%$ perendaman selama 6 hari (a) tanpa inhibitor (b) inhibitor 2000 ppm.

\section{KESIMPULAN DAN SARAN}

\section{A. Kesimpulan}

Berdasarkan hasil penelitian yang dilakukan maka dapat disimpulkan bahwa:

a. Pengaruh variasi konsentrasi inhibitor ekstrak daun beluntas terhadap laju korosi yaitu semakin besar konsentrasi ekstrak yang 
digunakan maka laju korosi semakin kecil dan efisiensi semakin besar. Laju korosi tertinggi diperoleh pada perendaman selama 6 hari tanpa adanya inhibitor yaitu sebesar 17,6305 mmpy pada metode weight loss dan 17,6432 mmpy pada metode polarisasi potensiodinamik. Sedangkan laju korosi terkecil pada perendaman 6 hari dengan konsentrasi inhibitor 2000 ppm yaitu sebesar 1,5451 mmpy pada metode weight loss dan 1,5477 mmpy pada metode polarisasi potensiodinamik.

b. Hasil karakterisasi baja karbon yang telah direndam dalam media $\mathrm{NaCl} 3,5 \%$ tanpa adanya inhibitor menunjukkan adanya lubang, retakan serta gumpalan yang lebih banyak jika dibandingkan dengan baja karbon yang direndam dalam media $\mathrm{NaCl} 3,5 \%$ dengan adanya inhibitor. Selain itu, kandungan Fe yang terdapat pada baja karbon tanpa adanya inhibitor lebih kecil dibandingkan baja karbon yang direndam dengan adanya inhibitor yaitu masing-masing sebesar $70,88 \%$ dan $77,83 \%$.

\section{B. Saran}

Berdasarkan hasil yang telah diperoleh dari penelitian ini, maka diperlukan adanya:

\begin{tabular}{llr} 
a. Pengujian & \multicolumn{2}{r}{ menggunakan } \\
instrumen GC-MS & untuk \\
mengetahui secara & spesifik \\
senyawa yang berperan & dalam \\
proses inhibisi korosi. &
\end{tabular}

b. Perlu dilakukan pengukuran laju korosi menggunakan metode yang lain, serta karakterisasi menggunakan instrumen XRD untuk mengetahui produk korosi (oksida besi) yang terbentuk.

\section{DAFTAR PUSTAKA}

Akmal, Imelda. 2009. Rumah Ide Baja Ringan Edisi 10/IV. Jakarta: PT. Gramedia Pustaka Utama.

Al-Mayouf, A M., Al-Ameery, A K and Al-Suhybani, A A. 2015. Inhibition of Type 304 Stainless Steel Corrosion in 2M Sulfuric Acid by Some Benzoazoles Time and Temperature Effects. Corrosion. 58.

Butar, B dan Febrianto. 2009. Instrumentasi eDAQ dan benda uji. 37-38.

Dalimartha, S. 1999. Atlas Tumbuhan Obat Indonesia jilid 1. Jakarta: Trubus Agriwidya.

El-Sherbini, F., Wahab, A., and Deyab, M. 2005. Ethoxylated Fatty Acids as Inhibitors for The Corrosion of Zinc in Acid Media. Materials Chemistry and Physics 89, 183- 191.

Gapsari, F. 2017. Pengantar Korosi. Malang: UB Press.

Handani, S., dan S.E. Megi. 2012. Pengaruh Inhibitor Ekstrak Daun Pepaya Terhadap Korosi Baja Karbon Schedule 40 Grade B Erw Dalam Medium Air Laut Dan Air Tawar. Jurnal Ris. Kim. Vol 5. No 2. pp 175-179.

Jones, Denny. 1992. Principles and Prevention of Corrosion. New 
York: Macmillan Publishing Company.

Koch, G.H., Brongers. M. P. H., Thompson. N. G., Virmani. Y. P., and Payer. J. H. 2001. Corrosion Cost and Preventive Startegies in the United States. Houston TX: NACE International.

Martimez, S and Stern, I. 2016. Inhibitor Mechanism of Low Carbon Steel Corrosion by Mimosa Tannin in Sulfuric Acid Solutions. Journal of Applied Electrochemistry.

Nurdin, Isdriayani dan Syahri. M. 1998. Inhibisi Korosi Baja Karbon

Oguzie, E. E., Wang, S. G., and Wang, F.H. 2009. Influence of Iron Microstructure on Corrosion Inhibitor Performance in Acidic Media. Journal of Phisical Chemistry. (19). 8420.

Priyotomo, G. 2008. Kamus Saku Korosi Material. Tangerang: Metalurgi LIPI.

Reimer, L. 1998. Scanning Electron Microscopy: Physics of Image Formation and Microanalysis. Heidelberg: Springer-Verlag.

Roberge, P. R. 2000. Handbook of Corrosion Engeneering. New York. McGraw Hill.

Rozi, Siska., Emriadi., dan Yeni Setiadi. 2014. Pemanfaatan Ekstrak Etanol Kulit Jengkol (Pithecellobium jiringa) sebagai Inhibitor Korosi Baja St. 37 dalam Medium Asam Klorida. Jurnal Kimia Unand. 3(1). 46.

Ryu, Hwa Sung., Chang G 1., Tae W k., Seungmin L., Hong T K and Sang H S. Evaluation of Corrosion
Resistance of Corrosion Inhibitor for Concrete Structures by Electrochemical Testing in Saturated $\mathrm{Ca}(\mathrm{OH}) 2$ Solutions with $\mathrm{NaCl}$ and $\mathrm{Na} 2 \mathrm{SO} 4$. Hindawi Advances in Materials Science and Engineering. ID 8294360.

Saputra, H., A. Syarief., Y. Maulana., dan J.L. Akhmad. 2014. Analisis Pengaruh Media Pendingin Terhadap Kekuatan. Jurnal Ilmiah Teknik Mesin Unlam. 3(2). 9198.

Sastromidjojo, H. 1991. Spektroskopi. Yogyakarta: Liberty.

Sari, Ayu K P., Ydni Sedialdim Idanutan Karbonat Bikarbon Emriadi. 2013. Pemanfaatan Ekstrak Daun Jambu Biji (Psidium guajava L). Sebagai Inhibitor Korosi Baja St. 37 dalam Medium Asam Klorida. Jurnal Kimia Unand. 2(4). 31.

Setiaji, D., dan Sudarman. A. 2005. Ekstrak Daun Beluntas (Pluchea indica Less.) sebagai Obat Antistres pada Ayam Broiler. Media Peternakan. 28(2). 46-51.

Sidiq, M dan Fajar. 2013. Analisa Korosi dan Pengendaliannya. Akademi Perikanan Baruna Slawi. Journal Foundry. 3(1).

Trethewey, K. R., dan Chamberlain. J. 1991. Korosi Untuk Mahasiswa dan Rekayasawan. Jakarta: PT. Gramedia Pustaka Utama.

Wulandari, A. 2011. Studi Ketahanan Korosi H2 pada Baja Karbon Rendah yang Mengalami Cabnai Hangat $600 \mathrm{oC}$. Skripsi. Jurusan Teknik Metalurgi dan Material Fakultas Teknik Universitas Indonesia, Depok. Jawa Barat. 
Ying Yan. 2008. Electrochemical and

Quantum Chemical Study of Purines as Corrosion Inhibitors for Mild Steel in $1 \mathrm{M} \mathrm{HCl}$ Solution. Electrochemica Acta. 53(20).
Yuningsih, Mitra., Emriadi., dan Yeni Stiadi. 2016. Ekstrak Daun Ekor Naga (Rhaphidophora Pinnata Schott.) Sebagai Inhibitor Korosi Baja dalam Medium Asam. Jurnal Kimia Unand. 5(3). 19. 